\title{
CREATING AN EVENT VOLUNTEERING LEGACY: THE 2014 HOST CITY VOLUNTEER INITIATIVE
}

\author{
ROBERT J. ROGERSON,* (1) FIONA REID, $\dagger$ AND RAFAELLE NICHOLSON + \\ *Institute for Future Cities, University of Strathclyde, Glasgow, UK \\ $\dagger$ Independent Researcher, Edinburgh, Scotland, UK \\ $\$$ Faculty of Management, Bournemouth University, Bournemouth, UK
}

\begin{abstract}
This article examines why as part of the 2014 Commonwealth Games in Glasgow, Glasgow Life failed to achieve its aspired legacy of promoting further volunteering by Host City Volunteers (HCVs) despite the implementation of best practice. This practice included providing dedicated funding of a volunteer legacy program, supporting recruitment from groups generally underrepresented among regular volunteers, and the provision of a dedicated team to support HCVs before, during, and after the event. Drawing on research conducted at the time of the event and a follow up study 3 years later, the article suggests that the absence of such legacy arose because, although highly motivated by the one-off prestigious event, the event volunteers were less motivated by other opportunities, many of those involved as event volunteers were already committed volunteers, and were reluctant to take over responsibility for engaging with future volunteering opportunities. The article considers the wider implications for future event managers seeking to generate volunteering legacies as part of major events. In so doing, it underlines that despite the scheme being constructed around the key characteristics of the much-lauded benchmark model of event volunteering associated with the Manchester 2002 Commonwealth Games volunteering legacies cannot be guaranteed. Even when there is success in engaging with people markedly different to the common type of event volunteer in underrepresented communities, translating their enthusiasm into postevent volunteering is problematic.
\end{abstract}

Key words: Event volunteering; Sporting mega-event; Legacy planning; Commonwealth Games

Introduction

Running for more than a decade after the original sporting mega-event, the Commonwealth Games of 2002, the Manchester Event Volunteers (MEV) has become a key benchmark and exemplar model by which to increase the chances that legacy aspirations associated with mega-sporting event volunteering can be achieved (Nichols, 2012; Nichols \& Ralston, 2012). Established to provide a volunteering legacy 
of the 2002 Commonwealth Games (Smith \& Fox, 2007), the MEV demonstrates that it is possible to convert some one-off and short-term volunteers at events into more committed volunteers involved with events and opportunities in the host city. Nichols and Ralston's (2012) review 8 years into the MEV existence underscored the importance of an organizational framework that provides leadership and funding to ensure that legacy planning can be continued after the event. These authors suggest that the absence of this reduces the opportunities to realize volunteering legacies, most clearly evidenced by the failures to support volunteer plans associated with the London 2012 Olympic and Paralympic Games (Girginov, 2012; Nichols, 2012; Nichols \& Ralston, 2014a).

In seeking to generate volunteering and social legacies from the 2014 Commonwealth Games in Glasgow, the City Council and its arm's length organization responsible for sport and culture, Glasgow Life, drew on the learning from the Manchester 2002 experience and other mega-events. It created a 3-year program, called "Host City Volunteers," spanning periods before, during, and after the event as it sought to use the event to foster new volunteers, civic pride, and benefits for communities.

This article considers the impact of the HCV program, extending the insights of the MEV experience to explore how despite being a specially devised volunteer legacy program the HCV initiative failed to deliver the transformational benefits sought. Using original research conducted with the HCVs over 3 years, the article offers insights into why positive changes to volunteering behavior were not achieved, and draws out lessons for future event management. The article initially outlines the key characteristics of the HCV program, before turning in the second section to position the HCV program alongside the critical factors identified in the MEV that could make a volunteering legacy more likely. It notes how learning from MEV shaped the HCV program, and how it sought to make improvements to fit into the different planning timescales of the two programs. Using the evidence of survey, interview, and focus group primary research with the HCVs explained and analyzed in the following two sections, the article discusses the explanatory factors that have reduced the positive impact of the HCV program. It concludes by discussing the implications for future events, especially at a time when event volunteering has often become a key element of wider legacy goals (Blackman et al., 2017; Koutrou et al., 2016).

\section{The HCV Program}

As part of the 2014 Commonwealth Games held in Glasgow, the largest sporting event ever held in Scotland, a team of $1,100 \mathrm{HCVs}$ were deployed across the city to complement the 12,500 venuebased volunteers named Clyde-siders recruited, trained, and managed by the 2014 Organizing Committee, Glasgow 2014 Ltd. The HCV program was independent of the organizing committee, a distinction that parallels aspects of the volunteering structures of 2012 London Olympics where the official volunteers termed Games Makers were augmented by local Ambassador volunteers, who like the HCVs were located in the areas surrounding venues (Nichols et al., 2017). Organization of the HCVs was undertaken by Glasgow Life, on behalf of Glasgow City Council, partly funded by the Big Lottery Fund alongside the two city-based partners.

This HCV program sought to utilize event volunteering opportunities at the 2014 Commonwealth Games as a means to encourage people to help overcome barriers to general volunteering, through improvement to their knowledge, skills, and confidence and to provide opportunities for local people to feel connected with, and have an active part in, delivery of the Games. Seeking to be more inclusive than the main event Clyde-sider scheme, and to encourage those without volunteering experiences and event-related skills-groups largely absent from the Clyde-sider volunteers - the HCV program was designed to run over a period of 3 years; in advance of the event, during the event, and for 12 months thereafter. Over this extended time period, the program not only sought to support future volunteering, but had ambitions of using the $\mathrm{HCV}$ roles to help enhance civic pride and to encourage HCVs to help their local communities.

A dedicated team was set up within Glasgow Life to recruit Host City Volunteers from across all communities in the city, primarily using existing networks to reach into communities frequently underrepresented in event volunteers and 
underrepresented among the Clyde-siders (e.g., people with disabilities, asylums seekers \& refugees, BME women, older people over 60 years). There was not an open public call for volunteers, and HCVs were either personally invited, or encouraged by local organization leaders to apply. Training for Games time roles was provided by Glasgow Life staff ahead of the event, and logistical support and volunteer welfare services was provided centrally in the city by Glasgow Life for all the HCVs. Following the event, HCVs were encouraged to contribute their memories and stories to a public exhibition housed in the People's Palace Museum in early 2015, with the showcase material codesigned by Glasgow Museum staff and HCVs (Glasgow Life, 2016). Glasgow Life also maintained contact by e-mail with those HCVs who gave permission to offer information about other volunteering opportunities ( $90 \%$ of the $\mathrm{HCVs}$ ), providing information about forthcoming event volunteering opportunities supported by the City Council, for the year after the Games. Beyond this, HCVs were directed to the long-established Volunteer Glasgow website, offering information about volunteer development and longer-term volunteering opportunities in communities in the city.

The profile of the HCVs recruited reflected the partial success of the program to be inclusive. Thirtyone percent reported that they had never volunteered before, $15 \%$ identified themselves as disabled, and $11 \%$ were aged 65 plus. Across the group, 38\% were considered "hard pressed" according to their Acorn CACI profile (Sly, 2018), those people who are finding life the hardest and experiencing the most difficult social condition including struggling families, burdened singles, and those finding hardship in high-rise or inner-city properties (CACI, 2010).

During the Commonwealth Games, held in July and August 2014, the HCVs were organized into teams, each with its own leader, and deployed across the city. They assisted with wayfinding and general information for spectators and visitors to the city during Games time, including information on: games venues; event times; transport links; the 2014 cultural program; and other city attractions and amenities. Most were deployed along "active travel routes" within the high footfall thoroughfares of the city center, and around the three "live zones" (Glasgow Green, Merchant City, and Kelvingrove
Bandstand), which were the central venues for the associated 2014 cultural program.

In contrast to the Clyde-sider volunteer scheme, there was flexibility in the number and duration of volunteering sessions expected of each volunteer, allowing them to select what worked within their own lives, a single orientation day in May 2014 for everyone involved in the programs, and individual information packs provided by Glasgow Life during the event.

\section{The MEV and HCV Initiatives}

The construction of the HCV program drew on the experience of and learning from other megaevent volunteering in the UK, including the (then) recent experiences of the Ambassador volunteer programs in London for the 2012 Olympic Games. The HCV program shared some important elements of the London Ambassador approach, including faster recruitment of volunteers, more flexibility in roles and shift times, and locally based volunteers (Harris, 2012). However, most learning came from MEV, reinforcing Nichols and Ralston's (2014b) conclusion that "it may be easier to link delivery and legacy, learning from and improving on the example of Manchester 2002" (p. 68) than from the larger 2012 Olympics. Opportunities were created for the civic partners involved in the HCV program to learn directly from those involved with $\mathrm{MEV}$, including from the assistant chief executive from Manchester City Council and a key member in the MEV development, Vicky Rosin. She served on Glasgow City Council's Legacy Board overseeing local initiatives and offered guidance to Glasgow Life and the City Council on lessons from Manchester 2002 and MEV.

In underlining the good practice aspects associated with MEV, Nichols and Ralston (2012) suggested that its development provides valuable lessons into critical factors necessary to allow volunteering legacies to be realized. In particular, their study highlights a range of key factors that were either present or absent from the Manchester 2002 legacy planning. Each of these were considered and addressed in relation to the HCV program (Table 1).

The HCV program had funding independent of that allocated to the running of the event itselfsimilar to the initial single regeneration bid (SRB), 
Table 1

Addressing the Key Factors Critical to MEV Success

\begin{tabular}{|c|c|}
\hline MEV Critical Factors (Nichols \& Ralston, 2012) & HCV Program Components \\
\hline $\begin{array}{l}\text { Program's initial SRB funds had been entirely independent of the } \\
\text { budget for running the Games }\end{array}$ & $\begin{array}{l}\text { The Big Lottery funding was separate from the budget } \\
\text { of the Games, dedicated to the HCV program }\end{array}$ \\
\hline $\begin{array}{l}\text { Specific legacy plans were not made in the immediate period before } \\
\text { the Games as the overriding imperative as to deliver the event suc- } \\
\text { cessfully, almost leading to insurmountable logistical problems }\end{array}$ & $\begin{array}{l}\text { The HCV program sought to plan ahead of the Games } \\
\text { for a program that was provided across the event }\end{array}$ \\
\hline There was a need for bidding for further funding after the event & $\begin{array}{l}\text { The program did not seek additional funding but sought } \\
\text { to mainstream into existing organizations supported } \\
\text { by the City Council }\end{array}$ \\
\hline $\begin{array}{l}\text { Important that key staff, who had an interest in generating the } \\
\text { legacy, remained after the Games and helping to set the direction } \\
\text { of the post-Games project }\end{array}$ & $\begin{array}{l}\text { A team of staff from Glasgow Life was created to pro- } \\
\text { vide continuity throughout the life of the program }\end{array}$ \\
\hline $\begin{array}{l}\text { Generating an integrated database of potential volunteers was not } \\
\text { planned for and was nearly lost }\end{array}$ & $\begin{array}{l}\text { A database was created and managed by Glasgow Life } \\
\text { with privacy permission sought to enable integration } \\
\text { with research and event planning }\end{array}$ \\
\hline $\begin{array}{l}\text { Essential to act quickly to contact all the Commonwealth Games } \\
\text { volunteers and PVP members to capitalize on their enthusiasm }\end{array}$ & $\begin{array}{l}\text { The program included a } 12 \text { month postevent set of con- } \\
\text { tacts and events to maintain contact with volunteers }\end{array}$ \\
\hline $\begin{array}{l}\text { Essential to have a volunteering opportunity to offer them after the } \\
\text { Games }\end{array}$ & $\begin{array}{l}\text { Glasgow Life had a program of events needing volun- } \\
\text { teers already scheduled including other major sporting } \\
\text { events, and regular city events }\end{array}$ \\
\hline $\begin{array}{l}\text { Management by local government helps to ensure a legacy and can } \\
\text { potentially work with an independent legacy budget }\end{array}$ & $\begin{array}{l}\text { The program was managed by Glasgow Life for the } \\
\text { City Council, and was part of the Games legacy } \\
\text { framework }\end{array}$ \\
\hline $\begin{array}{l}\text { Create a broker service post-event to promote volunteering } \\
\text { opportunities }\end{array}$ & $\begin{array}{l}\text { Connected with existing Glasgow and Scottish volun- } \\
\text { teer services, promoting opportunities to volunteer }\end{array}$ \\
\hline
\end{tabular}

Note. Source: Nichols and Ralston (2012) and authors' research.

which funded the Manchester 2002 prevolunteer program. This allowed the HCV team to create their own mechanisms to recruit and manage volunteers, aligned more closely to the ambitions set out in the local, Glasgow City Council legacy framework (Glasgow City Council, 2009), and to have an organizational structure that outlasted the event. The central role of Glasgow Life and the dedicated team of key staff throughout the life of the HCV program was important, ensuring there was continuing enthusiasm and commitment to the $\mathrm{HCV}$ aims and legacies. Like the small Manchester City Council team that oversaw the early development of MEV after 2002 Games, the Glasgow Life team continued to support the postevent exhibition, maintained contact with HCVs, connected with local voluntary organizations, and promoted HCV programs within the Council and Volunteer Glasgow.

With a small administrative team and short lead in time for $\mathrm{HCV}$ recruitment, a workforce management system was used, which enabled HCVs to request changes to their shifts and for vacancies and other information about shifts to be communicated by automatic SMS and e-mail alerts. The system also provided attendance recording to ensure that all locations were covered, and was able to detail exact dietary requirements to support each of the $\mathrm{HCV}$ teams at these locations. This assisted in making the approach adopted to the HCV program more aligned with a membership management approach (Meijs \& Karr, 2004).

However, the HCV program did not seek to replicate the MEV experience exactly. Unlike the SRB, which underpinned the development of the prevolunteer program and the early development of MEV, $\mathrm{HCV}$ was not offering opportunities to help train people to acquire qualifications from specific disadvantaged groups or for volunteers. The HCV training was tailored to the event time roles rather than generic skills assisting in other volunteering positions, more similar to that of the London 2012 Ambassador program. The HCV program also sought to address some of the perceived limitations of the MEV approach, especially in relation to preevent planning, utilizing event time experiences to ensure positive identities in the volunteering roles, and the need for continuing funding of a dedicated organization and structure to provide continuity after the event. 
Mindful of the "delivery imperative" that often becomes dominant in the months leading up to the Games - and which in the case of MEV and London 2012 meant specific plans for volunteering legacy were not developed (Nichols, 2012) - HCV was constructed with event time and postevent legacy processes in place. Thus, it sought to overcome the "almost ... insurmountable logistical problems" experienced in Manchester in 2002 (Nichols \& Ralston, 2012, p. 180) when contact mailing lists were nearly deleted before being retrieved to allow the MEV to be created.

The HCV initiative was not intended to be a longterm volunteer broker organization, in contrast to the way that the MEV evolved. Instead, over the first year after the 2014 event, volunteers were encouraged to engage with existing, mainstream volunteer development organizations, Volunteer Glasgow and Volunteer Scotland. Locally, the HCVs were directed towards Volunteer Glasgow, the civicfunded organization that supports volunteering in the city, and provides details of many event volunteering opportunities. This was reinforced by the encouragement of HCVs (and the Clyde-sider volunteers) to register with the online volunteer account created by Volunteer Scotland. As well as offering more tailored volunteer support, it also promoted forthcoming volunteering opportunities. In utilizing these existing channels, Glasgow Life sought to avoid the need to create a new, separate postevent volunteer organization for the long term, while also strengthening affinities to the city.

\section{Methodology}

Conducting research with event volunteers after the end of the event can be problematic. Contractual and privacy agreements are often in place under the processes of regulatory capitalism surrounding many of these events that makes continued contact with event volunteers difficult (Dickson et al., 2015; Lockstone-Binney et al., 2016; Nichols et al., 2017). Such logistical issues were avoided by the $\mathrm{HCV}$ program being managed by Glasgow Life, operating with their own database discrete from that of the Organizing Committee, and with a separate relationship to the research team. Members of the research team had been involved with the HCV program prior to the Glasgow Commonwealth Games and had established a relationship with Glasgow Life through evaluation of the program in 2014. Together, Glasgow Life and the research team had constructed mechanisms to enable contact to be maintained with the HCVs after the event, with $90 \%$ (993) of the HCVs providing consent to be recontacted for research purposes in future when they enrolled as HCVs, and 57\% (628) reiterating their consent after the Games were finished. In conducting the research, and to preserve anonymity of the HCVs, Glasgow Life acted as a broker, inviting the HCVs on their databases to respond to surveys. All the responses were anonymous. Participant identities in the interviews and in the focus groups were anonymized as part of the data recording process by the researchers.

As part of the longitudinal dimension of the research, surveys were conducted with the HCVs at their training session ahead of the Games, and again within a fortnight of the event ending in August 2014, surveys were conducted with a sample of HCVs (Table 2). These surveys primarily explored the HCVs preevent aspirations, their experiences of the $\mathrm{HCV}$ role, and their future volunteering intentions. Greater analytic depth was provided by 27 $\mathrm{HCVs}$, each being interviewed ahead of, during, and immediately after the event. The 27 interviewees

Table 2

Timetable of Surveys and Interviews with Host City Volunteers

\begin{tabular}{llcrr}
\hline Method & \multicolumn{1}{c}{ Date } & No. of Respondents & No. Approached & Response Rates \\
\hline Pre-Games survey & May 2014 & 838 & 993 & $84.4 \%$ \\
Games-time interviews & July-August 2014 & 27 & 27 & $100.0 \%$ \\
Immediate post-Games survey & August 2014 & 208 & 628 & $33.1 \%$ \\
Follow-on survey & August 2017 & 333 & 628 & $53.0 \%$ \\
Follow-on focus groups & September 2017 & 15 & 45 & $33.3 \%$ \\
\hline
\end{tabular}

Note. Source: authors' research. 
were recruited to reflect the demographic and volunteering history profiles of the HCVs group as a whole. The discussions were designed to identify motivations and aspirations of the role (preevent), practical issues, and benefits being experienced/ lived during the event, and their overall assessment of the benefits and impact of the role to them in terms of future lives and volunteering.

Three years on from the 2014 Games, Glasgow Life on behalf of the researchers recontacted the $\mathrm{HCV}$ s to encourage them to complete a follow-on online survey, with 333 (53\%) completing this. The follow-on survey sought to address the impact of being an $\mathrm{HCV}$ on their subsequent volunteering, and to provide an understanding of their behavior. Recognizing the importance of framing questions in an appropriate manner (Downward et al., 2005), the majority of questions in both surveys were adapted from those used in the UK General Household Survey, hence were pretested. Respondents were asked to indicate the nature and extent to which they were currently (in October/November 2017) involved in volunteering and to report on any change in their involvement since their pre-Games volunteering (i.e., before July 2014). As well as demographic information about their gender, age, ethnicity, postcode, and whether or not they considered themselves to have a disability or long-term illness, they were asked an open question indicating what impact being an HCV had on their lives. Although ethical requirements to preserve respondent anonymity meant that individual respondent data could not be matched with data from the 2014 study - as is suggested as the ideal by Dickson et al. (2015) - the profile of respondents was generally representative of the HCV population (Table $3)$. The younger age groups and those from ethnic minority groups were slightly underrepresented, and those identified as having a disability or longterm illness slightly overrepresented.

As with the Games-time approach, a second stage of the follow-on analysis involved the recruitment of a small sample of $15 \mathrm{HCVs}$ on the basis the survey results to participate in focus groups. Each group was organized to reflect the degree of change in their volunteering, or social and civic connections reported by the respondents to the follow-on survey. These groups enabled deeper interrogation of the survey results and exploration of the reasons for any change, or lack of change, in volunteering behavior. The discussions were transcribed and analyzed using NVivo. The survey results were analyzed statistically for correlations and associations.

\section{Results}

Research conducted with the HCVs immediately after the event highlighted that the event volunteering experience generated the role satisfaction, "feel good," and status, factors that previous studies have underlined as important to ensuring future volunteering (Dickson et al., 2015; Hyde et al., 2016; Nichols \& Ralston, 2012). Using a Likert scale of 1 (least) to 10 (most), 91\% of the HCVs surveyed in August 2014 rated their pride in being an $\mathrm{HCV}$ as 8 or higher, $80 \%$ were satisfied with their roles, and $64 \%$ felt more valued having been an HCV. There was also a strong sense of civic pride among the

Table 3

Profile of Host City Volunteers Surveyed: Percentages

\begin{tabular}{lcccc}
\hline & $\begin{array}{c}\text { Host City Volunteer } \\
\text { Population, July 2014 }\end{array}$ & $\begin{array}{c}\text { Pre-Games Survey, } \\
\text { May 2014 }\end{array}$ & $\begin{array}{c}\text { Immediate Post-Games } \\
\text { Survey, Aug 2014 }\end{array}$ & $\begin{array}{c}\text { Follow-on Survey, } \\
\text { Aug 2017 }\end{array}$ \\
\hline Age & & & & 11 \\
$16-24$ & 30 & 29 & 15 & 9 \\
$25-34$ & 14 & 16 & 10 & 11 \\
$35-44$ & 12 & 12 & 15 & 21 \\
$45-54$ & 17 & 17 & 24 & 23 \\
$55-64$ & 16 & 14 & 17 & 23 \\
$65+$ & 11 & 12 & 19 & 12 \\
Ethnic minority & 23 & 22 & 14 & 23 \\
Disabled & 15 & 14 & 9 & \\
\hline
\end{tabular}

Note. Source: authors' research. 
HCVs, with 78\% having more pride in Glasgow and $67 \%$ feeling more connected to the city. Further, the HCVs found their role rewarding for themselves (78\%), rewarding to be part of the Games $(87 \%)$ and part of Glasgow $(90 \%)$. There was an intention among the majority ( $83 \%$ ) of $\mathrm{HCVs}$ to continue volunteering. The interviews conducted with $27 \mathrm{HCVs}$ before, during, and after the event also reinforced that their role met expectations and the above motivational reasons for taking part. The strong desire to be part of the prestigious and unique event, to gain social benefits through meeting others, and achieve altruistic benefits of selfconfidence were widely acknowledged as having been achieved through the role (Rogerson et al., 2015).

Despite such strong foundations, 3 years after being $\mathrm{HCVs}$, the follow up research indicates that a clear HCV volunteering legacy struggled to be realized. Indeed, the proportion who were currently volunteering dropped to $61 \%$, a decline of $11 \%$ from the volunteering levels prior to 2014. The propensity for postevent volunteering to be focused on sporting events, including one-off events such as the Homeless World Cup (which was hosted by Glasgow in 2016) and local events like the Glasgow Half-Marathon, was not borne out across all the HCVs. Since 2014, only $30 \%$ of respondents had volunteered at another sporting event. There was a more positive outcome in terms of wider community engagement and development of social connections, with more than 1 in 4 respondents in the 2017 follow-on survey indicating that they more connected to their local community (Rogerson et al., 2019).

As noted above, the HCV program sought explicitly to target key groups of the population in the city that were known to be underrepresented as volunteers. Analysis of these groups also points to a gap between the expressed intentions at Games time and subsequent volunteering behavior. Amongst those residents in the most deprived areas of Glasgow-defined as the lowest decile on the Scottish Index of Multiple Deprivation - there was a decrease in levels of current volunteering, from $72 \%$ ( 23 respondents) volunteering pre-Games to $59 \%$ (19 respondents) currently volunteering. A similar pattern was found among those self-identified as having a disability or long-term illness, dropping from $75 \%$ (49 people) before the Games to $66 \%$ (43 people) volunteering now. Three years on, the HCVs are of course older, and thus perhaps less able to volunteer. However, the evidence from those older HCVs, now aged 65 or more years, was one of the few categories where there was a small rise in the proportion who currently volunteer, from $72 \%$ (49 people) to $78 \%$ (53 people). Among the other age groups, there was a general decline consistent with the overall findings.

There was some success in recruiting new volunteers through the $\mathrm{HCV}$ program- $31 \%$ of the $\mathrm{HCV}$ sad not previously volunteered - but among these there was also little evidence of long-term behavioral transformation. Of the 85 people in the follow-on survey who had not done any previous volunteering prior to becoming an $\mathrm{HCV}$, only 26 (31\%) had continued to be active volunteers following their role as $\mathrm{HCV}$, with the majority of them (70\%) having new volunteering roles only at other sporting events in the city. In this cohort, most commented on the HCV experience giving them selfconfidence, improved interactions with others, and encouragement to volunteer, as well as personal benefits. However, other personal barriers meant that improved confidence and an appreciation of the value of volunteering were not translated into continued volunteering behavior.

Thus, the overall conclusions from the HCV surveys point to the $\mathrm{HCV}$ program not having a significant impact in delivering new volunteers and reinforces existing research findings that intentions at the end of the event are poor indicators of actual volunteering (Dickson et al., 2015).

\section{Explanations for Absence of a Volunteering Legacy}

This research provides unique insight as to why the HCV program had limited success in creating a new cadre of volunteers and the desired volunteering legacy, despite adopting best practice in program management from previous mega-sport events held in the UK and beyond, and generating strong levels of satisfaction among the event volunteers.

Some important explanatory insights emerged from the focus group discussions with the HCVs, reinforcing the quantitative and qualitative information 
provided in the follow-on survey. One factor may be that the majority of the HCVs were committed volunteers $(72 \%$ of the HCVs were already volunteers) already involved in altruistic and social activities (Lockstone-Binney et al., 2016). Generating and measuring a legacy among this substantial group is challenging, as the impact of the event volunteering role is a continuation of previous volunteering behavior. Although the HCV program had a commendable proportion of nonvolunteers compared with many similar event volunteer programs $(31 \%)$, the recruitment process used by Glasgow Life created this legacy challenge. By using local networks and community partners - such as Glasgow Disability Alliance, Enable Glasgow, Age Scotland - and Glasgow Life's own "area teams" - there was a propensity to recruit those already active volunteers. For example, across the 15 participants in the focus groups, all but one (H2) identified specific pre-HCV roles as the "gateway" through which they were approached by Glasgow Life (Table 4, column 2).

As a result, following on from their HCV roles, most continued with existing volunteering, being active citizens within their communities and networks. Despite the special and unique position of the Commonwealth Games volunteering roles, the experience of the HCVs did not generate additional and different motivations beyond that already encouraging them to be regular volunteers:
I think most of us were involved before, and the Commonwealth Games was a great experience but we are just carrying on wanting maybe to do things for other people and meet other people. So, in a sense it is not new. (D1)

I think it was a wonderful experience, I loved every bit of it, but it hasn't sort of brought any changes at all. (L2)

I think what I was doing before is similar to what I'm doing now, and I'll continue to do that. (M2)

Second, this was reinforced by many of the HCVs themselves making a special and unique effort to be part of the event, under conditions where were unlikely to be repeated in relation to more regular volunteering:

I was busy beforehand, I made time for the Commonwealth Games, and I'm busy now. (J2)

I had to do it at night time . . . it was hard workmade the effort to accommodate role around work commitments, and noted the exceptional aspects of this-given permission and space to change into $\mathrm{HCV}$ uniform from her work uniform. (J1)

Such accommodation and personal sacrifice was encouraged and supported by Glasgow Life through its flexible approach to arranging shifts and the use of the management software systems to

Table 4

Interview Participants' Preevent Volunteering Networks and Experience

\begin{tabular}{llll}
\hline Participant & \multicolumn{1}{c}{ Gateway to HCV Recruitment } & \multicolumn{1}{c}{ HCV Profile } & \multicolumn{1}{c}{ Previous Volunteering Experience } \\
\hline B1 & Glasgow Life Walking group & Retired & \\
M1 & Girl Guide rainbow and Brownies groups & Low-income area & Community volunteer with Guides \\
S1 & Local library volunteer & Ethnic minority & Macmillan Cancer Support \\
J1 & Advert/e-mail through cooperative (work) & Nonvolunteer & No previous volunteering experience \\
E1 & Girl Guides & Full-time worker & Regional volunteer with Guides \\
D1 & Boys Brigade & Church volunteer, retired & Boys Brigade previously \\
C2 & Local Food Bank & Nonvolunteer & Local church \\
CC2 & Debt counselling advice service & Low-income area & Rejected Clyde-sider, works for a charity \\
L2 & Home library service & Low-income area, retired & Once a month community volunteer \\
M2 & Home library service & Low-income area & Volunteer with asylum seekers \\
H2 & Word of mouth & Non-volunteer, retired & No previous volunteering experience \\
J2 & Rotary & Home career & Previous event volunteer \\
L3 & Rejected Clyde-sider & Low-income area & No previous volunteering experience \\
& Childrenond London 2012 \\
F3 & Child panel & Home career & Lapsed volunteer \\
J3 & Council sport event volunteer & Retired & Volunteer at London 2012 in Glasgow \\
& & & and events \\
\hline
\end{tabular}

Note. Source: authors' research. 
allow HCVs to move shifts as needed. This enabled some of the volunteers to take on a role:

The opportunity was there ... (they could) accommodate you even if you worked part time (J1).

The uniqueness of the 2014 Commonwealth Games was important not just for the volunteers themselves, but also in enabling employers to offer support to assist HCVs, beyond that available to general volunteering. Some employers granted leave, or allowed employees to work part time (unpaid), while other employers offered more tangible support. For example, M1 was already involved in other volunteering and had to make additional time for the HCV role by using her annual leave. M1's employer offered additional support, saying "right you do 5 days - I was taking leave for it-we'll give you 2 and half days back." Such willingness to accommodate volunteering in a one-off event contrasted with the lack of flexibility in other volunteering roles where "the hardest part as well is doing everything out with your normal working hours" (J1). One-off prestigious events thus provide additional motivation and opportunity.

Thirdly, although the HCV program was not designed to be a broker service unlike the MEV, Glasgow Life continued to support the volunteers for the first year after the event, and as noted above provided opportunities to connect with Glasgow and national volunteer services. However, the absence of a discrete organization promoting future volunteering opportunities whose identity was itself connected with the event appeared significant. There was an absence of a sense of loyalty and connection with the Glasgow Games.

The HCVs readily acknowledged the value of Glasgow Life's continuing contact in the first year after the 2014 Games, but the subsequent emphasis on the HCVs to take their own responsibility to connect with future volunteering meant a loss of momentum:

The first year I kept getting emails . . . and Glasgow life were sending out loads of stuff. And then, it has kind of calmed down where you now have to do onto the website and look for stuff but you're not getting as many sent through. (E1).

Across each of the focus groups there was a sense that Glasgow Life (and the City Council more generally) missed an opportunity "to pull the volunteers" (M1). Typically, there was a feeling that: "It was a great pool, a resource, and they just didn't tap into it" (CC2); "I just feel that once it was over ... [there was] a resource they've not utilized since" (M2); and "they dropped the ball" (C2).

Although there was an acknowledgement that in the year after the end of the Commonwealth Games, and part of the HCV program, there was regular communication about event volunteering opportunities, these were not continued. In part this reflected a negative reaction to the expectation that HCVs would go online to find out opportunities, with use of social media including Facebook and Twitter not appealing to everyone, especially older volunteers and those already busy. More generally the experience of personal invitations being sent by Glasgow Life to encourage applications risked becoming normalized, generating expectations among the HCVs that they responded only to those who contacted them directly.

E1 summed up this mindset indicating that: "the things that I [have] done like the 'Beatson Walk' ... you go on a regular basis then they'll kind of contact you .... whereas other things they don't always contact you now" and consequently was no longer considering been actively involved with new volunteering.

\section{Implications and Conclusions}

The HCV program was constructed around the key characteristics of the much lauded "benchmark" model of event volunteering associated with the Manchester 2002 Commonwealth Games (Nichols \& Ralston, 2012) and best practice associated with the London 2012 Ambassador program (Nichols et al., 2017). Through a smaller, more targeted initiative designed to assist those least likely to be involved in volunteering to gain some insight and experience of event volunteering, the $\mathrm{HCV}$ program sought explicitly to create a legacy and not just to "deliver the event." The adoption of a more flexible membership management approach encouraged more volunteers unlikely and unable to be involved in more rigid and demanding event volunteering roles. However, as a corollary, this meant the use of existing community networks and the associated recruitment of many already committed 
volunteers. The evidence here suggests that despite success in creating considerable enthusiasm and pride in their roles as event volunteers, and a strong identity and affinity to the community, the program failed to generate the desired longer-term development of new or extended volunteering.

Although the HCV program encouraged one in three of those new to volunteering to continue after the event, engaging more people markedly different to the common type of event volunteer-described as uninterested in the event, feeling socially obliged to offer their services, and unsatisfied with the experience (Lockstone-Binney et al., 2015) - this proved also to be its Achilles heel. Several wider lessons can be learned from the HCV initiative.

First, the creation of new volunteers from oneoff, mega-sport events cannot be guaranteed, even if existing good practice is implemented, and a focused and dedicated program to support volunteer development is constructed and funded. Volunteering legacy relies on those involved in event volunteering taking on responsibility for future volunteering behavior and even the adoption of best practice as part of event volunteering management can only offer so much assistance towards a volunteering legacy. The expectation in Glasgow that by providing a constructive, well-managed, and positive event volunteering experience HCVs would be motivated to seek out new opportunities did not materialize.

Second, the adoption of existing networks to extend event volunteering recruitment to reach into local communities facing barriers to undertaking volunteering may be good practice (Ellard-Gray et al., 2015), but such networks are often composed of already active volunteers. In the context of Glasgow, few of the networks reached out beyond their existing members and, as a result, the $\mathrm{HCV}$ program legacy impact was constrained. If event managers are seeking to maximize a volunteer legacy of mobilizing a new cohort of volunteers, more time and resources need to be dedicated to creating new recruitment networks.

Third and most significant the HCV experience reinforces the need to provide dedicated resources after the event if legacy ambitions are to be realized. Like many city governments who host major sporting events, Glasgow sought deliberately to avoid creating, and thus having to finance and manage, a postevent organization, comparable to the MEV, to achieve its volunteering legacy. Instead, they sought to use existing resourced volunteer support and brokering agencies, seeking to "mainstream" the event volunteering into wider community volunteering. This failed to have the same impact that the MEV had following the Manchester 2002 Games, where the long-term connection with the major sporting event continued to exist. In Glasgow, in seeking to "hand over the baton" to other organizations there was a loss of identity and affinity with the event and its success. For the event volunteers, despite their clear intentions to continue as event volunteers, encouraged by the positive event experiences, this dissolution of the "brand" discouraged them to continue to be ambassadors for the city.

\section{Acknowledgement}

We are grateful to the all the Host City Volunteers who made time to contribute to this research, and to the staff at Glasgow Life for their invaluable support in enabling us to gain access to the volunteers. The helpful suggestions from the two referees for improving an earlier draft of the article are also acknowledged.

\section{ORCID}

Robert J. Rogerson: (D) https://orcid.org/0000-0001-6943-9263 Rafaelle Nicholson: (D) https://orcid.org/0000-0002-9128-201X

\section{References}

Blackman, D., Benson, A. M., \& Dickson, T. J. (2017). Enabling event volunteer legacies: A knowledge management perspective. Event Management, 21(3), 233-250. https://doi.org/10.3727/152599517X14942648527473

CACI. (2010). Acorn: The smarter consumer classification user guide. https://www.businessballs.com/freespecialresources/acorn-demographics-2010.pdf

Dickson, T., Darcy, S., Edwards, D., \& Terwiel, F. (2015). Sport mega-event volunteers' motivations and postevent intention to volunteer: The Sydney World Masters Games, 2009. Event Management, 19(2), 227-245. https://doi.org/10.3727/152599515X14297053839692

Downward, P., Lumsden, L., \& Ralston, R. (2005). Gender differences in sports event volunteering: Insights from Crew 2002 at the XVII Commonwealth Games. Managing Leisure, 10(4), 219-236. https://doi.org/ $10.1080 / 13606710500348086$ 
Ellard-Gray, A., Jeffrey, N. K., Choubak, M., \& Crann, S. E. (2015). Finding the hidden participant: Solutions for recruiting hidden, hard-to-reach, and vulnerable populations. International Journal of Qualitative Methods, 14(5). https://doi.org/10.1177/1609406915621420

Girginov, V. (2012). Governance of the London 2012 Olympic and Paralympic Games. In V. Griginov (Ed.), Handbook of the London 2012 Olympic and Paralympic Games, volume one: Making the Games (pp. 130-144). Routledge.

Glasgow City Council. (2009). Glasgow 2014 legacy framework. https://glasgow.gov.uk/CHttpHandler.ashx?id= $26935 \& \mathrm{p}=0$

Glasgow Life. (2016). 'Taking volunteering to the people. 'An evaluation of the host city volunteers (HCV) Programme. Final Report to Glasgow Life. https://prodglportalv2. azureedge.net/media/2421/hcv-partnership-working-coproduction-2016.pdf

Harris, M. (2012). London's Olympic Ambassadors: A legacy for public policy implementation. Voluntary Sector Review, 3(3), 417-424. https://doi.org/10.1332/ 204080512 X658108

Hyde, M. K., Dunn, J., Wust, N., Bax, C., \& Chambers, S. K. (2016). Satisfaction, organizational commitment and future action in charity sport event volunteers. International Journal of Nonprofit and Voluntary Sector Marketing, 21(3), 148-167. https://doi.org/10.1002/ nvsm. 1552

Koutrou, N., Pappous, A., \& Johnson, A. (2016). Postevent volunteering legacy: Did the London 2012 Games induce a sustainable volunteer engagement? Sustainability, 8(12), 1221. https://doi.org/10.3390/su8121221

Lockstone-Binney, L., Holmes, K., Smith, K., Baum, T., \& Storer, C. (2015). Are all my volunteers here to help out? Clustering event volunteers by their motivations. Event Management, 19(4), 461-477. https://doi.org/10.3727/ $152599515 X 14465748512605$

Lockstone-Binney, L., Holmes, K., Shipway, R., \& Smith, K. A. (2016). Evaluating the volunteering infrastructure legacy of the Olympic Games: Sydney 2000 and London 2012. Final Report; International Olympic Committee Olympic Studies Centre, Advanced Olympic Research Grant Programme 2015/16 Final Report. https://www. volunteering.com.au/wp-content/uploads/2016/09/ Final-Report-Evaluating-Volunteering-infrastructurelegacy-of-Syd-and-Lon-Olympics.pdf
Meijs, L., \& Karr, L. (2004). Managing volunteers in different settings: Membership management and programme management. In R. Stebbins \& M. Graham (Eds.), Volunteering as leisure, leisure as volunteering: An international assessment (pp. 177-196). CABI.

Nichols, G. (2012). Volunteering for the Games. In V. Griginov (Ed.), Handbook of the London 2012 Olympic and Paralympic Games, volume one: Making the Games (pp. 215-224). Routledge.

Nichols, G., \& Ralston, R. (2012). Lessons from the volunteering legacy of the 2002 Commonwealth Games. Urban Studies, 49(1), 169-184. https://doi.org/10.1177/ 0042098010397400

Nichols, G., \& Ralston, R. (2014a). The 2012 Ambassadors: Second class Olympic volunteers of the best potential for developing a volunteering legacy from the Games? In K. Smith, L. Lockstone-Binney, K. Holmes, \& T. Baum (Eds.), Event volunteering, international perspectives on the event volunteering experience (pp. 167-181). Routledge.

Nichols, G., \& Ralston, R. (2014b). Volunteering for the Games. In V. Griginov (Ed.), Handbook of the London 2012 Olympic and Paralympic Games, volume 2: Celebrating the Games (pp. 53-70). Routledge.

Nichols, G., Ralston, R., \& Holmes, K. (2017). The 2012 Olympic Ambassadors and sustainable tourism legacy. Journal of Sustainable Tourism, 25(11), 1513-1528. https://doi.org/10.1080/09669582.2017.1291648

Rogerson, R., Nicolson, R., Reid, F., \& Sly, B. (2019). Using major events to increase social connections: The case of the Glasgow 2014 Host City Volunteer programme. Journal of Policy Research in Tourism, Leisure and Events, 13(1), 94-106. https://doi.org/10.1080/19407963. 2019.1696351

Rogerson, R., Pavoni, A., \& Duncan, T. (2015). Participating as a Host City Volunteer: Perspectives from those involved in the Glasgow 2014 Commonwealth Games. https://prodglportalv2.azureedge.net/media/2417/ glasgow-2014-participating-as-a-host-city-volunteer-2015.pdf

Sly, B. (2018). Developing an events legacy. Presentation at the Sports Volunteering Research Network, October 2016.

Smith, A., \& Fox, T. (2007). From 'event-led to 'eventthemed' regeneration: The 2002 Commonwealth Games legacy programme. Urban Studies, 44(5-6), 1125-1143. https://doi.org/10.1080/00420980701256039 
Copyright of Event Management is the property of Cognizant, LLC and its content may not be copied or emailed to multiple sites or posted to a listserv without the copyright holder's express written permission. However, users may print, download, or email articles for individual use. 